\title{
Adaptability of Carbon Taxes and Carbon Trading in the Multimodal Transport Development
}

\author{
Zhigao Liao, a and Lunyue Wang ${ }^{2, b^{*}}$ \\ School of Management, Guangxi University of Science and Technology, Liuzhou 545006, China \\ aLiaozhigao@126.com, bwly_7069@163.com \\ *The corresponding author
}

Keywords: Carbon trading; Carbon tax; Multimodal; Low carbon

\begin{abstract}
The carbon trading and carbon tax abatement policy is now widely used for making low-carbon development of better intermodal, article or two abatement policies and multimodal combined by comparative analysis of the two mode of operation and multimodal economic cost optimization model to identify the requirements of low-carbon emission reduction policies in line with the development of multimodal transport. Using CPLEX software for solving the model, then by example and to verify the results were analyzed, the results showed that the carbon tax policy is more suitable for short-term development, and carbon trading policy is more suitable for long term development.
\end{abstract}

\section{Introduction}

At present, the global warming caused by uncontrolled emission of carbon dioxide and other greenhouse gases has caused widespread concern of governments and the public. Since the United Kingdom Government in 2003 in the "Energy White Paper" for the first time put forward the concept of "low-carbon economy", the various countries to take various measures to control greenhouse gas emissions, including carbon taxes and carbon emissions trading has been widely recognized. "China's response to climate change policies and actions in the annual report 2015 " clearly pointed out that by 2030 carbon dioxide emissions per unit of GDP than in 2005 fell $60 \%-65 \%$, according to "Stern report" data show that the global China's logistics industry fuel consumption accounts for about $34 \%$ of total consumption, carbon dioxide emissions accounted for $18.9 \%$, and take the road of sustainable development of low-carbon will be the inevitable trend of future development. The multimodal transport, with its huge transport capacity, lower transportation costs and relatively small pollution emissions and other unique advantages, become the world's priority mode of development of transport. Therefore, the choice of emission reduction policy in line with the development of low-carbon multimodal transport has become an urgent problem to be solved.

At present, most scholars at home and abroad focus on carbon tax and carbon emissions trading on the economic environment [1] - [4], Zhang Jinghua [5] believes that short-term carbon tax levy will raise prices of some products to curb economic development; and in the long run, people will seek low-power alternative products to reduce life and economic costs, environmental management costs also Decline, which will be more conducive to the sustainable and healthy economic development. Some scholars have studied the multimodal transport in combination of carbon tax and carbon emissions trading [6] - [9], but its main research is to reduce carbon emissions as a constraint to transport carbon emissions, such as Diabat [10] analyzed the influence of carbon quota on enterprise location decision and supply chain cost with constraint of carbon quota. J Bauer [11] pointed out that the greenhouse gas emission during multimodal transportation could be reduced by rationalizing the path and so on finally, from the point of view of government and enterprise, the optimization model of carbon emission constraint is established.

This study does not consider the carbon tax and carbon emissions trading in the development of low-carbon multimodal transport adaptability, so this paper will be from the characteristics of low-carbon multimodal transport, by comparing the two emission reduction model and The paper puts forward some suggestions for the low carbon development path suitable for multimodal 
transport.

\section{Operating Mode Comparison}

This paper focuses on the development of low-carbon multimodal transport in the process, carbon tax and carbon emissions trading which is more suitable for development requirements, so in this chapter, we first carbon emissions trading and carbon taxes in the multimodal transport mode of operation were compared.

Carbon Emissions Trading. In the carbon trading policy, we will participate in multimodal transport enterprises as controlled enterprises, within the scope of the policy, the total amount of carbon emissions is limited, and the form of emission quotas allocated to the controlled enterprises, with the most the appropriate path to achieve total control objectives. However, under the strict upper limit, part of the controlled enterprises can also through their own energy-saving emission reductions to the remaining carbon quotas in the form of carbon credits to the carbon trading market.

Participants. (1) government departments: the total control and transaction management, usually responsible for the allocation of carbon quotas and control the total carbon emissions.(2) controlled enterprises: the main participants in total control and trading, their emissions are subject to strict control of trading mechanisms, maturity must meet the emission reduction commitments in the case of a shortage of emission quotas need to buy carbon credits through the market to Offset their own carbon emissions. Controlled enterprises are the demand side of carbon credits.

Operation Flow. (1) Government departments to develop carbon cap: Government departments to develop emission reduction plan, in order to set a total emissions, and then according to the annual emissions of controlled enterprises to allocate carbon emissions. The government will achieve the emission reduction targets by strictly controlling the total amount of carbon emissions. (2) the establishment of carbon trading market: Controlled companies buy their own carbon credits. Controlled enterprises are required to reduce their own carbon emissions, must be energy-saving emission reduction, control corporate carbon emissions, the successful completion of emission reduction tasks of the controlled enterprises can be the remaining carbon credits in the form of carbon credits through carbon trading market sales to carbon emissions Controlled enterprises, in order to reduce their own costs.(3) the implementation of carbon sequestration projects: The government gets carbon credits through auctions of carbon quotas and uses carbon credits for carbon sinks to reduce carbon dioxide levels to offset the carbon emissions of controlled firms.

Carbon Taxes. Carbon taxes reduce fossil fuel consumption and carbon dioxide emissions by levying taxes on carbon-based fossil fuel products such as gasoline, jet fuel, and natural gas. Unlike market-based GHG mitigation mechanisms such as cap-and-trade and emissions trading, carbon taxes can be achieved with only a very small additional administrative cost.

Participants. (1) government departments: is the carbon tax policy managers, to develop a reasonable carbon emissions tax, and carbon emissions to the controlled enterprise levy fixed tax;(2) controlled enterprises: carbon tax collection targets, is the main source of carbon emissions, through the payment of carbon taxes to offset their own carbon emissions;(3) audit institutions: mainly audit the carbon emissions of the authenticity of controlled enterprises, is the carbon tax policy supervisor.

Operation Flow. (1) The enterprise calculates carbon emissions: Enterprises to calculate the annual carbon emissions through the consumption of fuel, and the results of the report to the audit department in the form of audits to determine the final year, the actual carbon emissions of controlled enterprises;(2) government departments to impose a carbon tax: Government departments to develop a reasonable carbon tax, according to the actual carbon emissions from controlled enterprises to impose carbon tax;(3) audit supervision: The auditing and supervision department first verifies the authenticity of the carbon emission report submitted by the controlled enterprise, and passes the result to the government department. The audit and supervision department is responsible for supervising and auditing the levying of the carbon tax of the controlled enterprise and ensuring the fairness of the whole process. Impartiality. 


\section{Model Data Analysis}

In this chapter, we will build the optimal model with the economic cost as the objective function under the carbon tax and carbon trading policy respectively. The following problems are to be solved: (1) To analyze the effects of different carbon policies on the multi- The impact of intermodal routes. (2) Comparative analysis of the advantages and disadvantages of the two policies. In order to facilitate the later analysis, the paper supposes that in the process of multimodal transport, we only calculate the carbon emissions during transport and the carbon emissions from transport modes.

Model Parameters. $V$ : Transport node $\left(V=V_{1}, V_{2}, V_{3} \ldots . . V_{n}\right) ; M$ : Transport mode $\left(M=M_{1}, M_{2}, \ldots, M_{n}\right) ; e_{i j a}$ : From "i"node to"j" node take "a" transport unit transport distance from the carbon dioxide emissions; ${ }_{i a b}: \mathrm{CO} 2$ emissions per unit of cargo that transitions from transport mode "a" to "b" at node "i"; $d_{i j a}$ : Using the transport mode "a" from the node "i" to "j" distance; $q$ : Total quantity of goods transported; $x_{i j a}$ : Whether the goods from node "i" to node " j" use "a" mode of transport; $y_{i a b}$ : Whether the goods are transferred from mode of transport "a" to "b" at node "i"; $c_{i j a}$ : The transport cost per unit of transport mode a is used from node "ij" to node " j"; $c_{i a b}$ : The cost per unit of goods transferred from transport mode "a" to "b" at node "i"; cap $_{i j a}$ : The transportation capacity limit of transport mode "a" is adopted From node "i" to node "j".

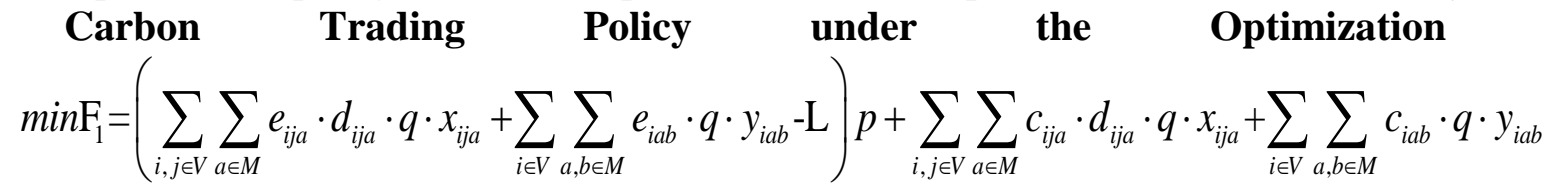

Model.

Where

"F1" represents the carbon cost of the controlled enterprise; " $L$ " stands for the carbon quota ceiling; "p" represents the price of the unit carbon credit on the carbon trading market;

$$
\sum_{i, j \in V} \sum_{a \in M} e_{i j a} \cdot d_{i j a} \cdot q \cdot x_{i j a}+\sum_{i \in V} \sum_{a, b \in M} e_{i a b} \cdot q \cdot y_{i a b}
$$

represents the total amount of carbon emissions during

the multimodal transport process and transshipment process;

$$
\sum_{i, j \in V} \sum_{a \in M} c_{i j a} \cdot d_{i j a} \cdot q \cdot x_{i j a}
$$

represents

the multimodal transport cost;

$$
\sum_{i \in V} \sum_{a, b \in M} c_{i a b} \cdot q \cdot y_{i a b}
$$

represents the conversion cost when the mode of transportation is changed.

$$
\begin{aligned}
& \sum_{a \in M}^{\text {S.t : }} x_{i j a} \leq 1 \quad i j=1,2,3, \ldots n \quad a \in M \quad \text { (1) } \quad \sum_{a \in M} \sum_{k \in M} y_{i a b} \leq 1 \quad i j=1,2,3, n \quad a \text { \& } \quad I \\
& x_{i j a} \cdot x_{j i a}=y_{j a b} \quad i j=1,2,3, \ldots n \quad a, b \in M \quad \text { (3) } \quad q \leq \text { cap }_{i j a} \quad i j=1,2,3, \ldots n \quad a \in M
\end{aligned}
$$

(1) and (2) show that the decision variables are $(0,1)$ variables; (3) if there is a transport path between the two nodes, there is only one path and only one transport mode;(4) transport mode "m"should be used from node "i" to node " $\mathrm{j}$ ",. The actual carrying capacity cannot exceed the carrying capacity of the section.

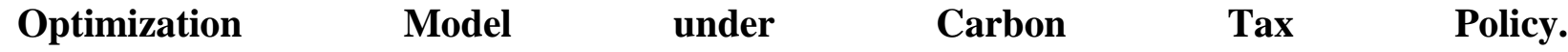

$$
\begin{aligned}
& \operatorname{minF}_{2}=r \cdot\left(\sum_{i, j \in V} \sum_{a \in M} e_{i j a} \cdot d_{i j a} \cdot q \cdot x_{i j a}+\sum_{i \in V} \sum_{a, b \in M} e_{i a b} \cdot q \cdot y_{i a b}\right)+\sum_{i, j \in V} \sum_{a \in M} c_{i j a} \cdot d_{i j a} \cdot q \cdot x_{i j a}+\sum_{i \in V} \sum_{a, b \in M} c_{i a b} \cdot q \cdot y_{i a b}
\end{aligned}
$$

Where "F2" represents the carbon cost of the controlled enterprise, " $r$ " represents the carbon tax, and (1) - (4) is established. 
Numeric Analysis. We assumes that a batch of goods starting from node " 1 " to the destination " 6 " through4 nodes. There are 3 kind of mode of transportation: roadway, railway, waterway from the Figure 1. The relevant data are given by the Tab.1-3 (distance of the 6 nodes, unit transportation costs, unit transportation time, et al.). The currently active carbon tax is 25 to 35 euros per ton in European, carbon tax repealed in Australia was $\$ 22$ per ton, France plans to levy a tax on carbon at 14 euros, the scope of a carbon tax of the national development and reform commission (NDRC), China is going to be 10-100 yuan/tons. Therefore, we choose the last one( 10-100 yuan/tons)and analysis the influence of the range of different carbon tax rate on multimodal transport. thesoftware CPLEX is used to solve the model.

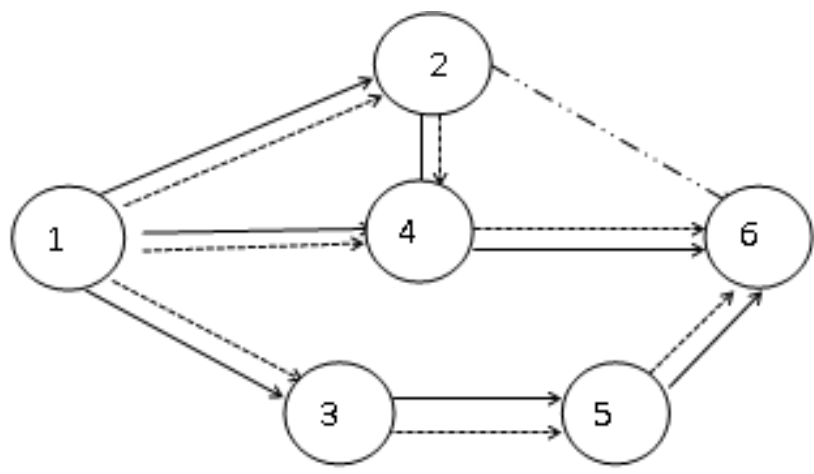

Figure 1. Multimodal transpotation case diagram

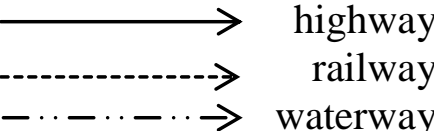

Table 1 Distance between nodes

\begin{tabular}{crrrrrrr}
\hline nodes & Road $(\mathrm{km})$ & Rail $(\mathrm{km})$ & Water $(\mathrm{km})$ & nodes & $\operatorname{road}(\mathrm{km})$ & $\operatorname{rail}(\mathrm{km})$ & water $(\mathrm{km})$ \\
\hline $1 \rightarrow 2$ & 300 & 450 & 0 & $2 \rightarrow 6$ & 0 & 0 & 300 \\
$1 \rightarrow 3$ & 250 & 340 & 0 & $3 \rightarrow 5$ & 180 & 0 & 0 \\
$1 \rightarrow 4$ & 230 & 300 & 0 & $4 \rightarrow 6$ & 210 & 0 & 0 \\
$2 \rightarrow 4$ & 200 & 280 & 0 & $5 \rightarrow 6$ & 150 & 0 & 0 \\
\hline
\end{tabular}

Table 2 unit transportation costs, unit transportation time

\begin{tabular}{lccc}
\hline & Road(km) & Rail $(\mathrm{km})$ & Water(km) \\
\hline $\begin{array}{l}\text { Unittransportation } \\
\text { costs (yuan / ton) }\end{array}$ & 15 & 13 & 11 \\
$\begin{array}{l}\text { Unit transit time(h / } \\
\mathrm{km})\end{array}$ & 0.3 & 0.2 & 0.4 \\
$\begin{array}{l}\text { Units of carbon } \\
\text { dioxide emissions (ton } \\
\text { / tonkm) }\end{array}$ & 0.04795 & 0.00841 & 0.01733 \\
\hline
\end{tabular}

Table 3 switching cost/time per unit and CO2emissions from different transport modes in China

\begin{tabular}{cccc}
\hline & $\begin{array}{c}\text { Unit conversion } \\
\text { costs (yuan /ton) }\end{array}$ & $\begin{array}{l}\text { Unit conversion time } \\
\text { (h/ton) }\end{array}$ & $\begin{array}{l}\text { Units of carbon dioxide } \\
\text { emissions (ton / ton) }\end{array}$ \\
\hline Road--Rail & 3 & 2 & 1.56 \\
Road--Water & 2 & 1 & 1.56 \\
Rail--Water & 2 & 2 & 1.56 \\
\hline
\end{tabular}


Data Processing. (1) carbon trading policy: Under the carbon trading policy, the controlled enterprise must first obtain the carbon quota"L" issued by the government. If the controlled enterprise's carbon emissions exceed "L", the controlled enterprise needs to purchase the carbon credits needed by the carbon trading market at the price "p"; If the controlled enterprise has the surplus carbon quota, may surpass the carbon quota in the form of carbon credits to the carbon trading market, thus reduces own economic cost. In this section, let "E" be the actual carbon emissions of the enterprise. By analyzing the relationship between "L" and "E", we can draw the following conclusions: 1) When $\mathrm{L}<\mathrm{E}$, The carbon cost of enterprises will increase with the increase of "p", and the choice of multimodal transport path will also lead to the choice of carbon transport with the growth of "p".2) When $\mathrm{L}>\mathrm{E}$, The firm will derive revenue from the carbon quota and increase as "p" increases.

(2) carbon tax policy:In the carbon tax policy, we do not set the maximum emissions of enterprises, government departments and enterprises directly from the amount of carbon emissions corresponding to the amount of tax, when $0<\mathrm{r}<52.3$, Multimodal transport path and transport the same way ( 1 road 4 rail 6), in this carbon tax rate range, the carbon tax will play a small role in the enterprise constraints, companies will choose the largest carbon emissions of multimodal transport route; When $r>52.3$, Companies will consider the cost of carbon tax, select the lowest carbon emissions line (1 rail 4 rail 6).

Comparison of Different Carbon Policies. Under the policy of carbon tax and carbon trading policy, the optimization model based on multimodal transport cost as objective function shows that under different carbon tax and carbon credit price, the cost of transportation enterprise will be different: In the carbon trading policy, the total cost of enterprises will increase with the carbon credit prices, but the cost of carbon emissions will increase with the carbon price of the first increase after the decline in the trend, and ultimately bring economic benefits to the enterprise; and carbon tax policy Under the total cost of enterprises is the carbon tax with the increase in the increase, for enterprises to bring an increasing cost of carbon emissions. Therefore, from the model point of view, the difference between the two is mainly the trend of carbon emissions costs.

\section{Conclusion}

In the context of the growing emphasis on environmental issues in the current context, this paper will be two different carbon-carbon policy and multimodal transport combined analysis, the results show that carbon trading and carbon tax policies are from the economic point of view, through Affecting enterprise transportation costs to control the enterprise transport path, and then guide the transport enterprises to low-carbon path development. Carbon trading policy is characterized by the need for enterprises to take the initiative to reduce their own carbon emissions to make their own carbon emissions less than it would have to pay additional costs to maintain their own carbon emissions, with a mandatory effect; compared to carbon tax policy, Government does not set a cap on carbon emissions, only based on transport enterprises carbon tax levy fixed tax, transport enterprises only need to consider the economic costs can be, do not need to consider the cap of its own carbon emissions. From the perspective of multimodal development, the implementation of carbon tax policy is low, but the lack of market regulation, carbon trading policy, although the implementation of high cost, but in the carbon trading policy, enterprises can get through the emission reductions to promote enterprise development Low - carbon multimodal transport. Therefore, in the short term development, carbon tax policy is more applicable, in the long-term development perspective; carbon trading can promote multimodal transport and the harmonious development of the environment. In the future research, we can also study how to coordinate the carbon cost allocation among the members of different transport network nodes so as to make the whole transportation network develop in harmony.

\section{Acknowledgements}

Guangxi Philosophy and Social Science Fund (The Grant No. 13BGL009) 


\section{References}

[1] R. Zhang, D. Chen and Y. Lin.: Forum on Science and Technology in China.2012, 5:57-63.

[2] T. J. Considine,D. F: 2009 31(2): 27-35.

[3] J.W. Wang.; Journal of International Trade.2011, 10:107-115.

[4] Y. Gao, K. Guo. : Studies of International Finance, 2012, 12:82-88.

[5] J.H. Zhang.: Modern Economic Research, 2010, 02:86-88.

[6] Jabali O, Woensel T V, Kok A G D.: Production \& Operations Management, 2012, 21(6):1060-1074.

[7] Elhedhli S, Merrick R.: Transportation Re- search Part D Transport \& Environ- ment, 2012, 17(5):370-379.

[8] Chaabane A, Ramudhin A, Paquet M.: International Journal of Prod- uction Economics, 2012, 135(1):37 -49.

[9] H.J. Zhang, J.Y. Zhang. : Chinese Journal of Management Science, 2015, 10:57-66.

[10]Diabat A, Simchi-Levi D.: Industrial Engineering and Engineering Management, 2009. IEEM 2009. IEEE International Conference on. 2010:523-527.

[11] J Bauer T B, Crainic T C. : Journal of the Operational Research Society, 2009,61(3): 530-542. 